\title{
Bernd Fuhrmann, Deutschland im Mittelalter. Wirtschaft - Gesellschaft - Umwelt
}

\section{Pierre Monnet}

\section{OpenEdition}

Journals

Édition électronique

URL : http://journals.openedition.org/ifha/8774

DOI : $10.4000 /$ ifha. 8774

ISSN : 2198-8943

Éditeur

IFRA - Institut franco-allemand (sciences historiques et sociales)

Référence électronique

Pierre Monnet, « Bernd Fuhrmann, Deutschland im Mittelalter. Wirtschaft - Gesellschaft - Umwelt », Revue de l'IFHA [En ligne], Date de recension, mis en ligne le 02 novembre 2017, consulté le 24 septembre 2020. URL : http://journals.openedition.org/ifha/8774 ; DOI : https://doi.org/10.4000/ifha. 8774

Ce document a été généré automatiquement le 24 septembre 2020.

(C)IFHA 


\section{Bernd Fuhrmann, Deutschland im Mittelalter. Wirtschaft - Gesellschaft - Umwelt}

Pierre Monnet

\section{RÉFÉRENCE}

Bernd Fuhrmann, Deutschland im Mittelalter. Wirtschaft - Gesellschaft - Umwelt, Darmstadt: Philipp von Zabern/WBG, 2017, 512 p., 79,95€ 
Encore une histoire nationale? Le titre, L'Allemagne au Moyen Âge, pourrait le laisser croire. Pourtant, on y chercherait en vain une histoire politique du SaintEmpire médiéval, de ses rois et empereurs et de ses institutions. Au contraire, et c'est sans doute là le signe intéressant d'une inflexion historiographique, le propos censé parler de l'Allemagne au Moyen Âge s'oriente résolument vers une réflexion de type culturel et social sur les fondements et les mutations des structures de ces pays «du milieu», entre France, Pologne, Hongrie et Italie. L'auteur ne s'en cache pas et précise dès l'introduction: il ne sera pas question de frontières territoriales, politiques ou religieuses, mais il s'agira de dégager une spécificité dans les modes de production, l'exploitation de la terre, la fondation des villages et des villes, la diversification des états et des groupes sociaux et la progressive monétarisation des échanges. On hésiterait à la qualifier de " germanique », car la dimension ethnique ou nationale n'est pas le niveau d'analyse visé ici, mais, à suivre Bernd Fuhrmann, elle présente au final une forme d'originalité et de subsidiarité qui en fait un modèle d'observation parmi d'autres en Europe. L'auteur n'entend pas reposer à nouveaux frais la sempiternelle question consistant à savoir si un certain type de climat ou de sol serait à l'origine d'un certain type de domination sur la terre qui trouvera en Europe sa transposition sous la forme de la féodalité et du prélèvement, tout d'abord parce que le débat retomberait dans un déterminisme anhistorique et ensuite parce qu'il n'y aurait au fond là rien de bien «allemand" par rapport aux autres régions. Il s'intéresse davantage à la dynamique sociale et économique qui, face à des conditions géographiques, climatiques, biologiques et humaines particulières, adapte ses formes, son extension et sa prolongation. C'est pourquoi chacun des trois volets du triptyque chronologique classique (Moyen Âge haut, central puis tardif) comporte les mêmes chapitres explicatifs : secteur agricole, artisanat, commerce, fait urbain, transports; seul le dernier volet, le plus volumineux d'ailleurs (350 pages sur 500, essentiellement en raison de la documentation plus abondante), consacré aux siècles finaux de la période, introduit des entrées plus fines : exploitation forestière, métallurgie, construction, monnaie et finances.

Le lecteur trouvera dans l'ensemble du développement le dernier état de la recherche, notamment archéologique, exploitant les résultats d'analyses qui traduisent, à partir de la documentation prise dans toutes les régions des pays allemands, un retour récent et certain des études d'histoire économique. C'est notamment le cas pour les données nombreuses et sérielles rassemblées sur les frappes monétaires massives des ateliers germaniques et bohémiens des $\mathrm{XIII}^{\mathrm{e}}-\mathrm{XV}^{\mathrm{e}}$ siècles (avant donc l'argent américain), sur le retournement des taux de crédit tant dans les campagnes que dans les villes rendant aux $\mathrm{XIV}^{\mathrm{e}}$ et $\mathrm{XV}^{\mathrm{e}}$ siècles le prêt moins cher, sur la diversification et la commercialisation des produits agricoles, sur l'émergence du problème principal en matière d'énergie, de 
matériau et de production que constitue le bois entre 1200 et 1500 . Avec les développements des pages 260-280 sur la construction des logements, c'est sans doute le chapitre consacré au bois qui apparaît en effet le plus neuf et le plus puissant: déforestation, inflation règlementaire, montée des conflits liés à l'exploitation... On retiendra ici les 20000 troncs livrés entre 1468 et 1488 pour la construction de la Frauenkirche de Munich ou, dans un autre ordre d'idées, les batailles rangées qui opposèrent, au milieu du XV siècle, dans les forêts du Palatinat ou de Bavière, les propriétaires de dizaines de milliers de porcs et les exploitants du bois. Si les chapitres consacrés à l'artisanat puis au commerce semblent plus classiques (Augsbourg, Nuremberg, la Hanse, les foires...), celui consacré aux métiers souligne cependant, là aussi, les aspects et les regards neufs de la recherche récente, notamment sur les petits métiers, la transformation intermédiaire, le recyclage et la maîtrise de l'énergie (les moulins !); de même que sont mises en relief, à raison, la spécialisation et l'expertise acquises par les métallurgistes allemands dès le XIII ${ }^{e}$ siècle auxquels sont consacrées de solides analyses aux pages 424-445 qui plongent en profondeur dans les gisements de Schwaz, du Harz et du Tyrol, sans oublier les énormes quantités de sels extraites des salines de Hall, de Salzbourg, de Lunebourg ou de Westphalie. Mais chaque fois, air du temps oblige, ce sont les répercussions souvent désastreuses de cette exploitation sur l'environnement qui, en croisant chroniques, procès, traités etc., sont pointées par l'auteur.

Ce qui se dessine sous nos yeux, c'est donc la mise en place d'un paysage économique et d'un écosystème d'exploitation (textile, métal, ressources minières, bois) aux origines du capitalisme et de l'industrialisation dont l'Allemagne, avec un fort effet de rattrapage à partir des années 1750/1800, deviendra en Europe l'un des grands pôles. De ce point de vue, le Moyen Âge allemand de B. Fuhrmann introduit une césure vers les $\mathrm{X}^{\mathrm{e}}-\mathrm{XI}^{\mathrm{e}}$ siècles et enjambe de loin le $\mathrm{XV}^{\mathrm{e}}$ siècle en plaidant, là aussi, pour un " long Moyen Âge ", non point stoppé mais justement à la fois dopé et prolongé par la pandémie des années 1350, les guerres confessionnelles, la construction concurrentielle des États princiers et royaux qui fouette l'expansion maritime (mais sans les pays allemands...), la production monétaire, les bonds technologiques militaires, l'inventivité de l'économie et de la fiscalité urbaines. Bref, l'histoire d'une variation « allemande » d'un modèle européen de développement sur le long terme.

\section{INDEX}

Index chronologique : Moyen Âge

Thèmes : Histoire sociale, Histoire des villes et des régions, Histoire économique, Histoire des milieux naturels 
AUTEURS

PIERRE MONNET

EHESS, Paris et IFRA-SHS, Frankfurt am Main 